\title{
Preparing student teachers for real classrooms through virtual vicarious experiences of critical incidents during remote practicum: A meaningful-experiential learning perspective
}

\author{
Saadet Korucu-Kış ${ }^{1}$ (D)
}

Received: 30 January 2021 / Accepted: 18 April 2021 / Published online: 23 April 2021

(c) The Author(s), under exclusive licence to Springer Science+Business Media, LLC, part of Springer Nature 2021, corrected publication 2021

\begin{abstract}
The Covid-19 pandemic has precipitated dramatic changes in education systems around the world and pre-service teacher preparation programs have been notably impacted by the associated difficulties and constraints. Due to lockdown of universities and schools, practicum placements had to shift from in-person to virtual learning environments. However, being a practical classroom activity, practicum posed particular challenges that prompted teacher educators to make adjustments in their pedagogical strategies to meet the course requirements. The present study reports on the first cycle of an action research project undertaken to respond to the practicum crisis caused by the Covid-19 restrictions. Conducted with eleven practicum students, this research investigated whether engaging student teachers in vicarious experiences of critical incidents through Kolb's experiential learning cycle via a collaborative virtual application could create meaningful learning. The results indicated that the intervention process had the characteristics of active, constructive, authentic, intentional, and collaborative, and as well it led to improvements in practicum students' domain-specific knowledge and skills. Despite a few number of concerns raised, which will be utilized to refine the future implementations of the first action plan, the practicum students reported that this experience supported them during remote practicum and contributed positively to their development. Drawing on the results of the study, a series of rationales for the use of virtual vicarious experiences of critical incidents during Covid-19 and beyond are provided.
\end{abstract}

Keywords Critical incidents · Practicum - Collaborative online technologies · Meaningful learning $\cdot$ Experiential learning $\cdot$ EFL student teachers

Saadet Korucu-Kış

skorucukis@gmail.com

1 Department of English Language Teaching, Necmettin Erbakan University, Konya, Turkey 


\section{Introduction}

Practicum constitutes a key element of teacher preparation. As the process of learning to teach culminates in field placements, it is also viewed as the most influential experience for student teachers. Along with engaging in linking theory to practice, developing skills related to classroom management, designing appropriate lesson plans, and evaluating different forms of assessment, it is during this process that student teachers "get to know the real world of schools and classrooms and what it means to interact with students, their problems and challenges" (Flores, 2016, p.204).

The Turkish Higher Education Council (HEC), the responsible body for "the strategic planning, coordination, supervision and monitoring" of all higher education institutions including initial teacher education programs (YÖK, 2019, p.6) mandates in-person visits to practicum schools. However, the physical closure of all educational settings as the result of the COVID-19 in Turkey as of mid-March 2020 severely interrupted face-to-face instruction and an emergency remote teaching plan was adopted by initial teacher education programs for the teaching of foundational courses of the spring semester of 2020. As to practice-based courses like practicum, student teachers had completed the first 6 weeks of the recommended 14 weeks in the second half of their field experiences by the time of the lockdown and in April, the HEC announced that teacher candidates would be assessed by university supervisors and cooperating teachers based on initial observations and evaluations already completed.

To date, there have been over two million Covid-19 cases and over twenty thousand deaths in the country. Given its incidence and mortality are on the rise, lockdown measures are in place and teacher education programs continue operating remotely. The same applies to the practicum courses in which student teachers have engaged in various remote learning experiences such as (a) observing cooperating teachers' activities online, (b) designing age and level appropriate materials, (c) developing lesson plans and implementing them under the supervision of mentor teachers and teacher educators, (d) holding discussions about their observations and performance with cooperating teachers and university supervisors through online chats or video conferences, and (e) keeping portfolios which include their lesson plans, materials and weekly reflections on their online practicum experiences. However, several researchers (e.g. Flores \& Gago, 2020; Moyo, 2020) argue that although such remote practicum practices may benefit student teachers in the development of their professional knowledge, it cannot capture the variety and complexity that inhere in the context of real classrooms which will enable them to link theory to practice. Nasri et al. (2020) further hypothesize that this lack of immersion in authentic educational settings will possibly pose problems for would-be teachers later in their professional lives.

Amidst growing concerns over the capability of remote practicum in facilitating the transition from initial teacher training to the workplace where novice teachers most often experience "the collapse of the missionary ideals formed during teacher training by the harsh and rude reality of everyday classroom life" 
(Veenman, 1984, p.143), getting student teachers to vicariously experience critical moments that will evoke hesitation, puzzlement and dissonance regarding teaching practice and having them deeply reason about the complexities of real classroom contexts in advance can be of strategic significance during the times of Covid-19 pandemic when student teachers have no access to educational settings and no opportunity to experience real-life dilemmas arising in physical classrooms. Critical incidents (CIs) defined as moments arising at unpredictable times and forcing teachers to make choices between different alternatives to intervene properly (Brubaker, 2015) may present themselves as unique opportunities to involve learners in such situations. Indeed, a number of studies (Chien, 2017; Farrell, 2008; Griffin, 2003) have highlighted the potential of CIs for "accelerated development" (Meijer et al., 2011, p. 117) at pre-service level. However, what was common to all these studies was that student teachers experienced critical moments in situ. Due to context-dependency of critical incidents (Babaii et al., 2020), no studies to date have investigated whether vicarious experiences of CIs can create meaningful learning experiences for them. To fill this lacuna, the present study attempts to find out whether having practicum students step into different teachers' shoes and handle teaching dilemmas that arouse in different contexts (Farrell \& Baecher, 2017) can support remote practicum in a meaningful way.

According to McLellan (2004), online learning environments are ideal for learning from dilemmas as they can mediate in-depth discussions resulting in resolutions from multiple points of view. Particularly, collaborative online technologies designed to facilitate the co-construction of knowledge allowing individuals to share, communicate, and exchange ideas (Hsu \& Shiue, 2018) can be of particular value when analyzing critical incidents. Affording student teachers the opportunity to make connections with their peers and instructors just as it is in bricks-and-mortar classrooms, collaborative technologies can create a learning community in which practicum students may come to terms with diverse perspectives over real-life teaching dilemmas.

However, the use of collaborative online technologies alone does not necessarily lead to learning. Grounding the design of online learning activities in pedagogically sound theories that encourage learners to construct, test, compare and evaluate models of phenomena results in the realization of the potential of technologies (Jonassen $\&$ Strobel, 2006). In order to create such an online learning environment, the meaningful learning theory (Ausubel, 1963; Jonassen, 1995) and the experiential learning model (Kolb, 1984) were utilized in the study. One reason to overlay the meaningful learning theory on the experiential learning model can be explained by the complementary relationship between descriptive and prescriptive learning theories in the design of courses. More precisely, while the meaningful learning theory described what principles (i.e. active, constructive, authentic, intentional, and collaborative) should underlie online learning environments and how their quality (i.e. process characteristics and outcomes) should be assessed, the experiential learning model prescribed a systematic approach to fulfill the promises of the meaningful learning in an intentional manner. It is hoped that the present study can provide insightful guidelines for teacher educators in times of Covid-19 pandemic and beyond to improve practicum experiences to be able to prepare student teachers for what they 
may encounter in real classrooms in the first years of their teaching often indicated as a period of reality shock (Farrell \& Baecher, 2017).

\section{Theoretical perspectives}

\subsection{A meaningful-experiential learning framework}

Grounded in the constructivist learning perspective, meaningful and experiential learning theories posit that learning occurs as a result of learners' interactions with their environments and involvement in a meaning-making process through which learners are able to intentionally link new information to prior knowledge that includes relevant ideas which the new knowledge can be connected to. In both theories, students are viewed as constructive agents who build knowledge and are capable of transferring that information to unfamiliar settings (Ausubel, 1963, 2000; Kolb, 1984). Underlined by the idea of the transformation of knowledge for meaningful learning-"the ultimate learning status for a learner"- to occur (Huang et al., 2011, p.2291), these theories place heavy emphasis on engaging learners in experiences that stimulate higher-order thinking. While meaningful learning theory describes what attributes these learning experiences should have, experiential learning model prescribes how to attend to these attributes in a sequential way.

As a descriptive theory, meaningful learning suggests that the achievement of meaningful learning can be defined by process characteristics and learning outcomes (Hakkarainen et al., 2007; Hakkarainen, 2009). Jonassen and Strobel (2006) and Howland et al. (2014) describe the process of meaningful learning as active, constructive, intentional, cooperative and authentic. Active learning involves mindful processing of information through analysis, synthesis and evaluation (Bonwell \& Eison, 1991; Jonassen, 1995). Constructive learning means reconciling feelings of disequilibrium through a reflective process of accommodating new knowledge into existing cognitive structures (Jonassen, 1995). In intentional learning, learners try to achieve a cognitive goal and responsibly monitor the process of fulfilling it (Jonassen, 1995). Authenticity refers to contextualized learning activities providing learners with the opportunity to deal with real world problems. Cooperation includes positive interdependence to solve dilemmas or build knowledge through social and internal negotiation of meaning (Hakkarainen et al., 2007; Jonassen, 1995). As to learning outcomes, they are identified through domain-specific knowledge and transferable skills (e.g. reasoning and problem-solving).

Although some inferences can be made from the framework of meaningful learning to guide the design of online learning activities, the theory does not offer a way of structuring a course. The experiential learning approach, on the other hand, illustrates the process of learning through a cyclical model consisting of four stages: concrete experience $(\mathrm{CE})$, reflective observation $(\mathrm{RO})$, abstract conceptualization (AC), and active experimentation (AE) (Kolb, 1984; Kolb \& Kolb, 2017). In the model, each component leads to the next attending to the principles of meaningful learning. To illustrate, in CE stage, learners are presented with real-life dilemmas that create puzzlement or cognitive dissonance to drive the learning process. In RO 
stage, learners reflect on the experience interacting both with the content and others (e.g. peers, instructors) to make meaning of the experience. Having clarified the issue, learners seek ideas from theoretical concepts to interpret the experience and offer possible solutions to the problems in the AC stage. The AE stage allows learners to directly or vicariously apply the new knowledge to decision making or problem solving (Svinicki \& Dixon, 1987). Bohon et al. (2017) suggest that since each component has distinctive elements that build upon the other to create meaningful learning, learners should involve in each stage of the model.

\subsection{Critical incidents}

Teaching is a complex profession fraught with many dilemmas ranging from internal (e.g. qualities of teachers, pedagogical problems) to external (e.g. institutional, political, societal) factors (Babaii et al., 2020). All of these variables have different peculiarities that may constrain teachers to implement the "right course" they intend to and challenge their sense of right action causing cognitive and emotional tensions in them (Shapira-Lishchinsky, 2011). Referred as critical incidents (CI), these unplanned events cause dissonance and result in the transformation of pre-existing cognitive schemata if reflected upon (Tripp, 1993).

The literature offers a number of definitions of critical incidents. Among others, McGarr and McCormack (2016) define CI as any event that causes a state of disequilibrium in teachers during instructional practices. In a similar vein, Farrell and Baecher (2017) view CI as an unexpected event that disrupts teachers' established practices and drives teachers to examine the values underpinning their actions. Harrison and Lee (2011) refer to CI as "any observable experience or activity that presents itself as an important or significant personal episode, and affords analysis" (p.200). Despite varying definitions, the common understandings that underline CI involve disruption, unpredictability, an event, and no instant solution (Brandenburg \& McDonough, 2017).

Research indicates that engaging student teachers in formal analysis of CIs allows them to reconsider their preconceived notions of teaching, accommodate their ideals with classroom realities, and make informed decisions and intervene properly when they arise (Farrell, 2008; Hall \& Townsend, 2017). It is also acknowledged that discussions on critical incidents at pre-service level can stimulate "accelerated development" (Meijer et al., 2011, p. 117).

Due to their potential benefits, CIs have been used in a number of studies in the context of pre-service teacher education. In a qualitative study conducted with eighteen student teachers, Farrell (2008) found that reflecting on different critical incidents that arouse in their team teaching sessions made teacher candidates realize that there were no one-shot solutions to most of the dilemmas faced during teaching practice. Involving six trainee teachers in a process of writing, discussing and analyzing CIs during their practicum, Chien (2017) investigated the possible effects of this implementation on student teachers' professional growth. The study concluded that practicum students experienced improvements in terms of procedural knowledge when handling CIs. In a supervised field experience, Griffin 
(2003) investigated whether writing CIs would develop practicum students' critical and reflective thinking skills. The results showed that CIs positively influenced student teachers' inquiry and growth in critical reflection.

As indicated in the studies above, critical incidents at pre-service level can stimulate "accelerated development" (Meijer et al., 2011, p. 117). Hence, helping practicum students understand the types of critical incidents they may experience in practice and how these problems of practice can be resolved may be of strategic significance particularly during the times of Covid-19 pandemic when student teachers have no access to educational settings and no opportunity to experience real-life dilemmas arising in physical classrooms.

\subsection{Collaborative online technologies}

With the widespread proliferation of Web 2.0 technologies, more collaborative virtual spaces such as Google Applications, blogs, wikis and forums were developed to facilitate goal-oriented activities and task-specific interactions (Cheung \& Vogel, 2013). According to Hsu and Shiue (2018) online collaborative environments provide a common platform that allows students to discuss, share and exchange ideas; interact with their peers, instructors and the content; co-construct knowledge and develop a sense of belonging to a learning community. As learning occurs as a result of social interactions (Vygotsky, 1978) and collaborative technologies afford enriched learning activities and increased participation, Ishtaiwa and Aburezeq (2015) further that collaborative tools improve academic success and performance.

Among others, the use of Google Docs has been of particular value in higher education contexts for the accomplishment of group works, tasks and projects. Specifically, the real-time co-editing function of this collaborative tool provides different affordances for both instructors and students. Just as in real classrooms, instructors can monitor and track student work and provide immediate feedback (Ebadi \& Rahimi, 2019). This function of Google Docs increases teaching presence which is essential for learners to achieve meaningful and valuable learning outcomes (Anderson et al., 2001). As to learners, they can communicate and negotiate ideas synchronously and revise and edit their work in interaction with their peers. Moreover, while collaborating in a common task, learners engage in discussions and interactions and learn from each other and the instructor either through making comments or chatting. Asynchronous communication is also possible and as well different versions of ideas can be monitored and tracked (Lin et al., 2016). Indeed, empirical research has revealed various educational benefits of using online collaborative technologies in learning environments such as enhancing motivation (Lin et al., 2016), increasing the learning of content knowledge through social interactions (Hsu \& Shiue, 2018) and facilitating the interplay between the elements of collaborative online learning settings identified by Curtis and Lawson (2001) as learner-instructor, learner-learner, learner-content, and learner-interface interactions (Ishtaiwa \& Aburezeq, 2015).

Farrell (2008) indicates that working collaboratively on problematic cases can engage learners in productive interactions and introduce them to many and varied perspectives. Given CIs are events with no simple straightforward cause-effect 
solutions, the extant literature (e.g. Farrell \& Baecher, 2017) highlights the potential of collaboration to approach these ill-structured problems to reduce the limitations of individual work. According to Lipponen and Lallimo (2004), collaborative technologies enable and scaffold "the construction of communal ways of seeing, acting and knowing, and production of shared knowledge and new practices for successful future action" (p. 436). In this regard, collaborative online technologies can be leveraged as promising knowledge building spaces to help practicum students interact with their peers and instructors, pool knowledge and skills as to the resolution of CIs, and subsequently develop shared understandings about the nature of CIs.

\section{Purposes and significance of the study}

Although critical incidents were acknowledged to be context-dependent in the literature, helping practicum students understand the types of dilemmas they may experience in practice and how these problems of practice can be resolved seem as logical possibilities during the times of Covid-19. In view of the fact that no studies to date have investigated whether vicarious experiences of CIs can create meaningful learning experiences for remote practicum and discussions on critical incidents at pre-service level can stimulate "accelerated development" (Meijer et al., 2011, p. 117), this study engages practicum students in an experiential learning cycle through written accounts of CIs and attempts to find out whether experiencing CIs vicariously offer meaningful contributions to remote practicum from student teachers' viewpoint. To assess the efficiency of this implementation, the following research questions were formulated:

1. Do Google Docs-mediated vicarious experiences of CIs create a meaningful learning process from the viewpoint of practicum students?

2. Do Google Docs-mediated vicarious experiences of CIs help practicum students achieve meaningful learning outcomes?

3. What implications arise from the results for the refinement of the action plan?

\section{Methodology}

In response to the challenges posed by the Covid-19 pandemic in field placements, the present study adopted an action research case study approach (Sturman, 1997) to bring about improvements in the delivery of practicum instruction. Since action research focuses on issues that are of immediate concern to educators and intends to produce desirable outcomes through small-scale interventions (Cohen et al., 2007), it emerged as a highly relevant methodology to guide the study. Moreover, a qualitative research tradition was selected as the present study aimed to find out how participants interpreted their experiences of the pedagogical intervention at issue. 


\subsection{Participants and context}

Eleven practicum students participated in the study. All the participants were female and their ages ranged from 21 to 31 . The students were enrolled in a practicum course in an English language teaching (ELT) program in Turkey. The official online course on practicum was offered for a 14-week semester and delivered via a web conferencing system, Adobe Connect during the fall semester of 2020. In these online sessions, practicum students engaged in a variety of activities such as having discussions with their supervisors about (a) the instructional activities undertaken in the practicum schools they were required to observe via Zoom throughout a 12-week semester, (b) materials and lesson plans they were assigned to design for different levels and age groups, and (c) controversial methodological issues as to the teaching of English language skills (e.g. error correction).

\subsection{Procedure}

Action research involves a cyclical process and consists of four stages: planning, action, observation, and reflection (Burns \& Rochsantiningsih, 2006; Kemmis \& McTaggart, 1988). The planning stage entails identification of the problem and development of an action plan. Accordingly, in response to practicum crisis caused by the Covid-19, the instructor researcher developed an action plan drawing on literature on experiential learning, meaningful learning, critical incidents and collaborative online technologies to support remote practicum practices. The action stage involved the implementation of the action plan and lasted for eight weeks. The participants met their peers and instructor virtually on Google Docs twice a week. All activities of the pedagogical intervention were guided by Kolb's experiential learning model. Figure 1 displays the elements and procedure of the research.

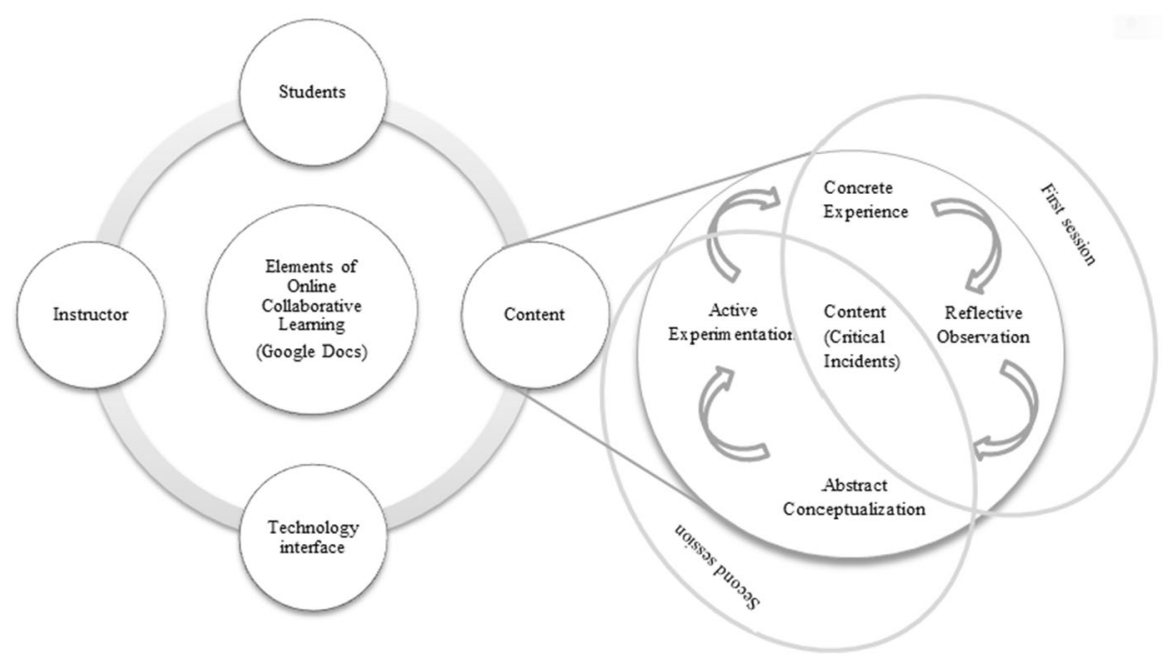

Fig. 1 The elements and procedure of the study 
Throughout the intervention, a number of prompts were used to guide the online activities. According to Sadaf and Olesova (2017), "When instructors ask questions that require integrating ideas and solving problems, students tend to critically examine the problems by exchanging viewpoints, exploring applications to problems, and synthesizing ideas to provide solutions, which are representative of the higher levels of cognitive presence" (p.59). In the first session of each week, practicum students engaged in the concrete experience (CE) and reflective observation (RO) phases. During the CO stage, the participants were presented with a CI including details about what happened, who was involved, how it affected the subjects, and when and where it occurred. The sample CIs were taken from Farrell and Baecher (2017) and some of the teaching dilemmas analyzed in this research study included establishing the teacher role in novice years, using the mandated textbook, and teaching mixedlevel classes. For the RO stage, the instructor first gave such discussion prompts as "If you were that teacher, how would you feel/what would you do?" Second, the participants were provided with the immediate reaction of the actual teacher and pushed by the following prompt: "Did you find the actual teacher's response appropriate? Why/why not?". Having written their individual responses, the practicum students engaged in a process of reading and exchanging views on other participants' reactions through making comments. Eliciting different cognitive processes, this stage was intended to allow learners to consider varying perspectives over the same issue and make better sense of the experience. At the end of the first session, the practicum students were asked to contemplate on the possible sources of the problem and search for alternatives to deal with the CI. The second session included involvement in the abstract conceptualization (AC) and active experimentation (AE) phases. During the AC stage, practicum students drew on theoretical concepts and empirical work and as well communicated with their mentor teachers, university instructors and previous school teachers to identify the underlying factors that created the problem and find solutions to address the CI thoroughly. This phase aimed to help practicum students make informed decisions about pedagogical dilemmas referring to domain-specific literature. For the AE stage, all the participants and the instructor shared ideas regarding the possible factors that caused the CI and offered solutions. This phase was guided by the following prompts: "What did you do to solve the problem?", "Could you compare your first and second reactions to handle the CI?", "What do you think about the group members' ways of solutions?", "How do you synthesize the new knowledge with your own proposed solutions?" and "How do you think the proposed ideas will help you, handle the CI?". In line with these questions, every group member examined other alternatives and reflected on each response brought by their peers and the instructor. The participants made comparisons between their first reactions and the new knowledge they gained. They were also asked to synthesize big ideas they explored during the sessions and draw conclusions about the experience. Throughout the process, Google Docs was actively used by the learning community. As it is a free online software, all the participants were able to access the application. It offered a space for saving documents created on the server and facilitated ubiquitous learning via online/offline working affordances. Its user-friendly interface made it possible to use it with ease. It allowed both synchronous and asynchronous communication. Particularly, the real-time co-editing and chat features of Google Docs 
increased opportunities for interaction just as in real classrooms. Its comment feature was also of high pedagogical value since it facilitated receiving and giving feedback. Moreover, it allowed learners to share large amounts of information and support their texts with images, graphs, tables and links.

\subsection{Instruments}

Data for this study came from multiple qualitative sources including discussion posts, reflective journals, and a focus group interview in order to gain in-depth insights into the efficiency, process characteristics and outcomes of the intervention. The discussion posts were used to find out the process characteristics of the intervention in real time and the learning outcomes achieved by the participants in each session. Student teachers were also asked to submit weekly reflections upon the completion of discussions on each CI. As a qualitative data collection method (Bashan \& Holsblat, 2017), reflective journals offered student teachers a place to express their thoughts, ideas, emotions and feelings concerning the analysis process of CIs and allowed the researcher to develop understandings of the practicum students' meaning making from the outset of the study. To investigate practicum students' overall perceptions of their engagement in vicarious experiences of CIs, a focus group interview was also conducted. The interview included ten semi-structured questions inquiring into practicum students' (a) perceptions of the affordances and limitations of the intervention (e.g. "Do you find the formal learning activities undertaken during remote practicum adequate for your future career? If yes, how? If no, why?, "Do you think this intervention has contributed to your professional learning? If yes, in what ways? If no, why?"), (b) aspects of the intervention they liked the most/the least (e.g. "What did you like most about the intervention?", What did you like least about the intervention?") and (c) recommendations to refine the pedagogical intervention (e.g. "Do you suggest the instructor to use this intervention in her future classrooms?", "What are your suggestions for the instructor to improve the quality of this intervention?"). The practicum students' responses to these tools allowed the instructor-researcher to carry out the observation stage of action research which includes the examination of the effects of the action plan by means of data collected (Burns \& Rochsantiningsih, 2006).

\subsection{Data analysis}

The present study employed a deductive-inductive analysis method by first applying an earlier theory and then inductively developing categories from the text material (Cohen et al., 2007). In other words, the pre-established constructs of the meaningful learning framework led the two coders including the researcher to adopt an intermediary position between "the a priori and inductive approaches" (Miles \& Huberman, 1994, p. 61). During the analysis procedure, the coders situated themselves primarily in the main frames of process characteristics (i.e. active-constructive, collaborative, authentic and intentional) and learning outcomes (domain-specific knowledge and transferable skills) of the meaningful learning approach; yet remained open to emergent patterns and understandings (Cohen et al., 2007). As a further note, in a recent study, Lee (2018) suggested that 
although the traits of being active and constructive were presented as distinct constructs within the framework of meaningful learning, they very much overlap. In similar veins, Mayer (2004) explains the intersection of active and constructive learning and states that "A common interpretation of the constructivist view of learning as an active process is that students must be active during learning" (p.14). Concurring with these researchers, the constructs of active and constructive are used as a single unit of meaning during the coding process. In other words, they are not considered as distinct; rather overlapping.

In line with the explanations above, the researcher first designed an unconstrained matrix of analysis which allowed the coders to not only develop categories within the bounds of the preconceived notions but also generate typologies inductively (Elo \& Kyngäs, 2008). Next, transcripts of discussion posts were reviewed and content was coded for correspondence to pre-determined categories. In the interim, emerging patterns were noted, codes were clustered and broader categories were generated for induction purposes. Text from the transcripts that fit the identified categories was matched to appropriate typologies in the matrix. The text consisted of either a meaningful sentence or a group of sentences with a clear intention. To triangulate the findings drawn from the discussion posts, the constant comparative method (Cohen et al., 2007) was used and the same analysis procedure was applied to reflective journals and responses to interview questions. In this way, the newly acquired data were constantly compared with the existing data to detect consistencies and inconsistencies across the instruments. In order to further the rigor in coding and accurate categorization, a negotiated coding approach (Garrison et al., 2006) was adopted. In the pilot coding, a subset of data from each source was independently analyzed by the researchers in alignment with the required coding protocol, discussions were held over the discrepancies detected, a final set of codes was settled upon and thereafter the actual coding process was initiated. In addition to peer debriefing, a number of other strategies were utilized to establish the trustworthiness of the study (Creswell, 2007). Thick descriptions throughout the paper intended to help the readers understand the transferability of the study. The use of multiple sources of data (i.e. discussion posts, journals and focus group interview) prevented mono-method bias and ensured triangulation. Moreover, member-checking of the data by the participants was an attempt to achieve congruency between the practicum students' expressions and the instructor-researcher's interpretations. In order to address ethical concerns, a written informed consent briefing about the significance and purpose of the study, asking for giving consent for voluntary participation and informing about the ensurance of anonymity and confidentiality was signed by all of the participants.

\section{Findings}

In this study, practicum students vicariously experienced a number of CIs and involved in collaborative inquiry to handle these dilemmas going through Kolb's experiential learning cycle. Analysis of the discussion posts, reflective journals and focus group interviews comprised a total of three overarching themes and seven main categories. The themes pertain to process characteristics, learning outcomes, and implications 
Table 1 The codes, sub-categories, categories and themes derived from the data

\begin{tabular}{|c|c|c|c|}
\hline Themes & Categories & Sub-categories & Codes \\
\hline \multirow[t]{10}{*}{$\begin{array}{l}\text { Process Charac- } \\
\text { teristics }\end{array}$} & \multirow[t]{3}{*}{$\begin{array}{l}\text { Active-Con- } \\
\text { structive }\end{array}$} & Sense of disequilibrium & $\begin{array}{l}\text { feeling inadequate, being challenged, } \\
\text { feeling frustrated, feeling vulnerable, } \\
\text { feeling puzzled, feeling surprised, feeling } \\
\text { impelled }\end{array}$ \\
\hline & & Thinking skills & $\begin{array}{l}\text { questioning, discussing, analyzing, reflect- } \\
\text { ing, criticizing, evaluating, making } \\
\text { decisions }\end{array}$ \\
\hline & & Sense of reconcilement & $\begin{array}{l}\text { feeling satisfied, feeling relieved, feeling } \\
\text { confident }\end{array}$ \\
\hline & \multirow[t]{3}{*}{ Intentional } & $\begin{array}{l}\text { Reflecting on prior edu- } \\
\text { cational experiences }\end{array}$ & $\begin{array}{l}\text { thinking on previous teaching experiences, } \\
\text { thinking on previous class teachers' } \\
\text { behaviors }\end{array}$ \\
\hline & & $\begin{array}{l}\text { Consulting more knowl- } \\
\text { edgeable others }\end{array}$ & $\begin{array}{l}\text { consulting mentors, consulting previous } \\
\text { class teachers, consulting instructors }\end{array}$ \\
\hline & & Literature review & $\begin{array}{l}\text { searching the internet, scanning method- } \\
\text { ology books, reading blogs, attending } \\
\text { forums, reading articles, searching the } \\
\text { Internet, using Google Scholar }\end{array}$ \\
\hline & \multirow[t]{2}{*}{ Authentic } & $\begin{array}{l}\text { Real-world } \\
\text { dilemmas }\end{array}$ & $\begin{array}{l}\text { experiencing similar events as a student, } \\
\text { observing similar dilemmas in previous } \\
\text { schooling experiences, encountering } \\
\text { similar dilemmas as a teacher, consid- } \\
\text { ering the dilemma as a countrywide } \\
\text { problem, considering the problem as a } \\
\text { common concern }\end{array}$ \\
\hline & & $\begin{array}{l}\text { Real-life like experi- } \\
\text { ences }\end{array}$ & $\begin{array}{l}\text { meeting with friends, meeting with the } \\
\text { instructor, synchronous interactions, } \\
\text { discussing as in real classrooms, asking } \\
\text { questions as in real classrooms, getting } \\
\text { feedback from the instructor as in real } \\
\text { classrooms, using emojis to reveal feel- } \\
\text { ings, using chat box to converse with } \\
\text { friends, using multimedia to support } \\
\text { ideas }\end{array}$ \\
\hline & \multirow[t]{2}{*}{ Collaborative } & $\begin{array}{l}\text { Positive interdepend- } \\
\text { ence }\end{array}$ & $\begin{array}{l}\text { negotiating meaning, developing shared } \\
\text { understanding, becoming aware of multi- } \\
\text { ple viewpoints }\end{array}$ \\
\hline & & $\begin{array}{l}\text { Establishing a com- } \\
\text { munity }\end{array}$ & $\begin{array}{l}\text { sense of belonging, peer support, instruc- } \\
\text { tor support }\end{array}$ \\
\hline $\begin{array}{l}\text { Learning out- } \\
\text { comes }\end{array}$ & $\begin{array}{l}\text { Domain- } \\
\text { specific } \\
\text { knowledge }\end{array}$ & Content knowledge & $\begin{array}{l}\text { the use of native language, discourse } \\
\text { competence, sociolinguistic compe- } \\
\text { tence, strategic competence, assessment } \\
\text { types, adaptation of language materials, } \\
\text { language ego, risk-taking, out-of-class } \\
\text { study, teaching listening, teaching } \\
\text { speaking, teaching writing, teaching } \\
\text { vocabulary, strategies-based learning, } \\
\text { integrated-language skills }\end{array}$ \\
\hline
\end{tabular}


Table 1 (continued)

\begin{tabular}{|c|c|c|c|}
\hline Themes & Categories & Sub-categories & Codes \\
\hline & & Pedagogical knowledge & $\begin{array}{l}\text { learner variables, procedure check, lesson } \\
\text { planning, classroom management, self- } \\
\text { monitoring, peer observation, group work, }\end{array}$ \\
\hline & $\begin{array}{l}\text { Transferable } \\
\text { skills }\end{array}$ & Self-directed learning & $\begin{array}{l}\text { relating new concepts to existing ones, } \\
\text { utilizing different resources to solve } \\
\text { problems, attempting to look at problems } \\
\text { from different perspectives, changing } \\
\text { strategies to resolve problems, starting } \\
\text { to question suggested solutions, feeling } \\
\text { interested in CIs, starting to think that } \\
\text { there is always a way out for problems } \\
\text { of practice, reflecting on weaknesses, } \\
\text { reflecting on strengths }\end{array}$ \\
\hline & & Problem-solving skills & $\begin{array}{l}\text { understanding the problem, working on } \\
\text { solutions, evaluating alternative solu- } \\
\text { tions, critical thinking, synthesizing } \\
\text { solutions, vicariously applying the solu- } \\
\text { tions, drawing conclusions }\end{array}$ \\
\hline & & Evidence-based reasoning & $\begin{array}{l}\text { seeing the relationship between theory and } \\
\text { practice, understanding the value of theo- } \\
\text { retical knowledge to overcome real-life } \\
\text { problems, and applying theory to practice. }\end{array}$ \\
\hline \multirow[t]{3}{*}{ Implications } & $\begin{array}{l}\text { Refinement } \\
\text { needs }\end{array}$ & Time-taking & large group size, hard work \\
\hline & & Technical difficulties & freezing page problems, sync problems \\
\hline & & Scope & very young learners, young learners \\
\hline
\end{tabular}

arising from the results for the refinement of the action plan (see Table 1). To show the data sources, a number of abbreviations were used while quoting the excerpts. "ST" stands for student teacher and is followed by a random number selected by each participant to ensure anonymity. "DP" refers to discussion posts, "RJ" to reflective journals and finally "FGI" to focus group interviews.

\subsection{Process characteristics}

Process characteristics that occurred throughout the pedagogical intervention reflect how going through Kolb's experiential learning stages drawing on CIs created a meaningful learning process for student teachers during remote practicum. The first characteristic was active-constructive that was coded when there were indicators showing that students teachers experienced a sense of disequilibrium (e.g. frustration, puzzlement, inadequacy) upon the introduction of critical incidents and subsequently felt a sense of reconcilement (satisfaction, relief, confidence) after engaging in a process of meaning making from what is known to new through different thinking processes (e.g. questioning, analyzing, reflecting and evaluating). The extracts below exhibit some of these indicators: 
I know that students are always curious about their teachers' personal lives but I don't know how open I should be with my students about my privacy...So, I felt really vulnerable when I read this problem and I don't know what to do if I face such questions... At the end of the second session, we came up with various effective solutions. I no longer feel helpless. I am more relieved now. (RJ, ST4) Why did the student seem to escape into a fantasy world during class hours?", "Does he have psychological, social or emotional problems?", "Why did the teacher bring the loss of points into question in such a situation?", "Was it because she was being observed by the school director and feeling anxious?" I need to answer these questions to start solving this dilemma... (DP, ST7)

The second characteristic was intentional that was identified as taking responsibility and action to manage the experiential learning based on CIs. The initiatives undertaken by the practicum students to deal with teaching dilemmas included using their previous educational experiences as starting points (i.e. applying their own knowledge and utilizing their prior school teachers' practices), collaborating with more knowledgeable others (i.e. mentors, instructors and school teachers) and peers as well as conducting a literature review by means of various sources (e.g. the Internet and books). To illustrate,

I had experienced a similar problem while attending supplementary classes at a private school. One of the students was not taking my work serious that day and asked me a nonsense question in the middle of the class. I got frustrated but was aware that I had to keep calm and go on teaching. I remember that I had used my mimics to show my disapproval and it had worked. So, I think mimics, gestures and posture are among the most important tools a teacher needs to have in her toolbox. (DP, ST6)

Having pondered the problem for several times, I decided to talk to my previous school teachers. Yet, I thought their suggestions would fall short of solving the problem. Therefore, I extended my research to read articles and check my methodology books. (RJ, ST5)

The characteristic of authentic was applied to both CIs and the interactions taking place via Google Docs by the practicum students. Regarding the former, the indicators emerged as having been involved in a similar event as a student, having observed a similar dilemma in prior schooling experiences, having encountered a similar dilemma as a teacher and considering the dilemma as a countrywide or common problem. Some of these indicators can be seen in the following excerpts:

When I heard the problem, my school life flashed before my eyes. I was like these students. Although I had a good knowledge of formal English, I was not able to talk in English fluently in the classroom as I didn't know how to use the language colloquially. (RJ, ST2)

The use of L1 is one of the most frequently encountered problems in language classrooms in our country. (FGI, ST3)

As to the authenticity of activities carried on Google Docs, the participants noted that coming together with their peers and instructor as in real classrooms, 
asking questions, discussing and exchanging ideas on the problem through the chat box, working synchronously, being able to use multimedia to support their ideas as they would do in typical classrooms and using emojis to reveal their feelings allowed them to enjoy real-life like experiences in times of Covid-19 pandemic. To exemplify,

Due to lockdown caused by the Covid-19 pandemic, we couldn't have faceto-face classes. However, we were able to communicate and interact with our instructor and peers via Google Docs whenever we wanted. It was a very beneficial application with several features that helped us carry out various real-world tasks like chatting, discussing thanks to comment add-on and working together simultaneously as in university-based courses. (FGI, ST4)

The final process characteristic was cooperation that was coded when such indicators as positive interdependence (i.e. negotiating meaning, developing shared understanding, and awareness of multiple perspectives) and development of a learning community (sense of belonging, instructor support and peer support) were recognized. To illustrate some of them:

ST11:... I think the more input our students get, the better they will talk. So, we need to support speaking activities with listening.

ST6: ...With your recommendation based on integrated skills approach, you helped me remember the natural link between speaking and listening skills. This made me revise, evaluate and expand my suggestions. Thank you. (DP)

I felt too inexperienced to deal with these problems most of the time but attempting to resolve them interacting with my classmates and instructor made me feel I was not alone. We developed relations, criticized and praised each other, inspired and got inspired from others, we were members of a learning group and we were developing together. (FGI, ST4)

\subsection{Learning outcomes}

According to Hakkarainen (2009), improvements in domain-specific knowledge and transferable skills can account for learning outcomes from a meaningful learning perspective. With these two main frames in mind, the analysis of the data revealed five subcategories indicating areas in which the practicum students reported showing improvements. The participants' conceptual achievements in domain-specific knowledge encompassed increases in content knowledge and pedagogical knowledge. For instance,

As a teacher candidate, I know that I should make as little use of our mother tongue as possible in our language classrooms yet I wasn't sure to what extent we can. Thanks to this CI, I learnt that I can utilize it while negotiating disciplinary and management issues, explaining abstract and cultural concepts, giving instructions and delivering brief explanations of language structures. (RJ, ST 10) 
"In order to warn this challenging student, I said I was going to tap on his shoulder lightly when I was passing by him. However, after doing research on this issue, I learnt about the rules of proxemics and kinesthetics.” (DP, ST 8)

As to the transferable skills displayed by the practicum students as a result of taking part in the current pedagogical intervention, the sub-categories of self-directed learning skills, problem-solving skills, and evidence-based reasoning skills were generated. The sub-category of self-directed learning skills developed based on the following indicators: relating new concepts to existing ones, utilizing different resources to solve problems, attempting to look at problems from different perspectives, changing strategies to resolve problems, starting to question suggested solutions, feeling interested in each week's CI, and reflecting on the strengths and weaknesses of the research conducted to deal with the CIs. The indicators of understanding the problem, working on solutions, evaluating alternative solutions, synthesizing solutions, and vicariously applying the solutions to problems referred to the development of problem solving skills in the practicum students. Finally, seeing the relationship between theory and practice, understanding the value of theoretical knowledge to overcome real-life problems, and applying theory to practice indicated the growth of evidence-based reasoning in the practicum students. The extracts below exhibit these themes:

Every week, our professor presented different critical events and the actual teachers' initial reactions to these dilemmas. Delving into each detail, I was trying to infer the reasons of the problem. Even if I exchanged ideas with my friends over the reasons of and solutions for problems, I was on my own while clarifying the problems, doing research and making decisions on how to resolve it. Most of the time, I was trying to handle the problem based on my existing knowledge. When it was inadequate, I was doing research...Then, I came to see that every problem had a solution and I was feeling satisfied and motivated when I was able to track the right way to handle the case. (RJ, ST11) Although I was not sure where to start to solve the problems during the first weeks of the meetings, my problem solving skills developed as I tried to search for ways of solution. First, I was trying to understand the problem and identify the reasons that caused it. Then, I was doing research, finding potential ways of solution, reading my friends' suggestions, evaluating them altogether, determining my intervention, re-evaluating it with my friends and drawing conclusions. (FGI, ST3)

When I did research on related critical incidents, I understood that theoretical knowledge that we learnt in our campus-based classes was indeed of great use for our professional lives. I saw that we can use them to solve classroom problems effectively. (FGI, ST8)

\subsection{Implications arising for the refinement of the intervention}

In terms of implications regarding the refinement of the action plan, the practicum students primarily stressed the challenge of time as a serious concern that should 
be taken into account to improve the intervention. Due to the large group size, the participants stated that evaluating all group members' activities and drawing conclusions based on them required considerable time. At the same time, increasing concerns were identified from the data regarding technical difficulties faced during the last weeks of the intervention. The practicum students indicated that they started to have freezing page problems as the number of the pages in Google Docs was increasing and the changes they made were not synced at times. The final concern voiced by the participants was related to the scope of the critical incidents. It was expressed that except one, other CIs were concerned with teacher-related problems, and secondary and high school level students. The following excerpts illustrate these points:

... it required dedicated hard work. Doing research on the possible reasons and solutions of the problems, reading all 10 peers' first reactions, reflecting on them, analyzing after-research solutions and assessing them, and answering questions posed by our friends or instructor related to the ambiguous part of our research was rather time-taking. Although such a large group was beneficial in terms of providing a rich variety of perspectives, small groups might have been better for time efficiency. (FGI, ST11)

... As the size of the Google Docs increased, we started to have problems with freezing pages and synchronization. (RJ, ST 7)

Another weakness of this class was that it focused on incidents taking place at late primary, secondary and high schools. I was also wondering about problems related to young learner classrooms... (FGI, ST 10)

\section{Discussion and conclusions}

Due to the Covid-19 related shutdown of schools and universities, in-person practicum serving as a bridge between academic coursework and actual practice have been suspended and moved online leading to serious concerns about how student teachers would qualify and enter the workforce (Flores \& Gago, 2020; Moyo, 2020). In this midst of uncertainty and complexity, teacher educators had to shoulder the responsibility to find alternatives to ensure student learning in distanced learning environments and support student teachers' transformation into confident beginning teachers. In a similar line of attempt, this action research case study was designed and aimed to create meaningful learning experiences to support practicum students engaging them in an experiential learning cycle benefitting written accounts of critical incidents. Moreover, practicum students' perceptions of the learning process and learning outcomes were examined and implications arising from the results were detected to take opportunities to refine the first action cycle.

Identifying the process characteristics that occurred throughout the intervention constituted the first goal of this study in order to understand whether the intervention worked out to create meaningful learning experiences for the practicum students. Findings revealed that four main elements of the meaningful 
learning framework were clearly apparent throughout the process. The participants reported that both the critical incidents and Google Docs-mediated activities offered them real-life like experiences. Regarding the authenticity of CIs, findings indicated that the participants found the critical events quite immersing since they either associated them with their prior schooling experiences or considered them as the perennial problems prevalent in the context of foreign language teaching in Turkey. As to the authenticity of activities, the participants stated that Google-Docs served as a shared tool which enabled them to work on real-world tasks meeting with their peers and instructor, express their feelings in various ways through emojis, informally converse with their friends through chat box and support their ideas by means of multimedia as in real classroom environments. These findings corroborate the ideas of McLellan (2004) who suggests that online learning environments provide meaningful learning experiences if they are designed around contextual tasks. Closely related to the authenticity of activities were the recurrent constructs of active-constructive, intentional and cooperative. it was apparent from the data that challenged by pedagogical dilemmas, the practicum students felt a sense of disequilibrium (e.g. frustration, puzzlement) which provoked them to first go through various thinking processes (e.g. questioning, analyzing, reflecting) to understand the CI thoroughly, then engage in intentional efforts (i.e. utilizing prior learning experiences, literature review and collaborating with more knowledgeable others) to handle the dilemma, and finally engage in higher-order thinking experiences (e.g. synthesizing, evaluating) to resolve the problem to achieve a sense of satisfaction. Consistent with the literature (Brandenburg \& McDonough, 2017; Farrell, 2008; Griffin, 2003; Hall \& Townsend, 2017), these findings suggest that critical incidents with no instant solutions cause dissonance in teacher-learners and stimulate taking goal-oriented actions to reach a state of equilibrium. As for the construct of cooperative, the complexity of the authentic dilemmas prompted the practicum students to frequently negotiate meaning with their peers and instructor. The constant exchange of ideas made them aware of multiple perspectives and helped them develop shared understandings and a sense of learning community. These results reflect those of Farrell (2008) who states that student teachers collaboratively reflecting on CIs are "better placed to face the realities of teaching in that they have come to realize that there are no single cause/effect solutions to the various dilemmas they may encounter in a language classroom" (p. 10).

Concerning the learning outcomes, the participants stated that dealing with CIs led to improvements in their knowledge of content and pedagogy. The intricacy of the dilemmas prompted them to search for more detailed information to properly understand the reasons underlying the CIs and resolve them. This finding seems to be consistent with other research (e.g. Karami et al., 2013) indicating that engaging student teachers in collaborative authentic problem-solving activities enhance their knowledge of subject matter. Chien (2017) had also found that practicum students experienced improvements in terms of procedural knowledge when handling CIs. In addition, the results showed that the practicum students experienced developments in the transferable skills of self-directed learning, problem-solving and evidencebased reasoning. The participants reported that they were feeling rather inadequate 
to deal with the CIs specifically during the first few weeks of the intervention. However, they maintained that as they began to make sense of the problem solving processes and regulated their efforts to successfully resolve the dilemmas, they felt more confident and proficient to come with purposeful activities and relevant solutions. This is in alignment with research indicating that involving student teachers in formal analysis of CIs allows them to reconsider their preconceived notions of teaching, make informed decisions, become more confident and intervene properly if they face those dilemmas in the future (Farrell, 2008; Hall \& Townsend, 2017). Evidence-based reasoning which is of vital importance to link university learning to practice was another recurrent theme related to the development of transferable skills. The participants noted that they came to realize that pedagogical dilemmas could be solved by drawing on theory. This finding broadly supports the ideas of Farrell and Baecher (2017) discussing that encouraging and training student teachers to handle pedagogical problems grounding their decisions in disciplinary knowledge is one of the ways to bridge the theory-practice gap.

In terms of implications, refinement needs regarding group size, technical issues, and the scope of critical incidents constituted the main lessons drawn from the first cycle of this action plan. The participants had difficulties in particular with managing time while exchanging ideas with other group members $(N=11)$ in order to respond to the questions guiding them through the cycle of Kolb's experiential learning. The practicum students stressed that although working with a large group offered multiple perspectives on a single issue, it required considerable time and hard work by them. The first lesson we take from this concern is that, forming small groups around critical incidents will be more convenient. The second issue raised by the practicum students was concerned with freezing pages and synching problems as the file size increased. Despite the functionality of Google Docs in offering an interactive virtual classroom, finding alternative web-based applications with similar features can be a way of solution or the formation of small groups may also help fix the problem. The final concern was about the content of the critical incidents presented. The participants stated that they wished to have worked on dilemmas encountered in very young learner/young learner classrooms as well. Considering the fact that the study included only one CI centered on a late young learner, selection of CIs from all school levels might have better satisfied the practicum students' needs.

Reflection constitutes the last stage of action research and involves the evaluation of plan, action and observation. In view of all these discussions, we conclude that despite a few number of weaknesses that will inform the future implementations of the present action plan, the implementation supported meaningful learning as delineated and operationalized in the study. The emergence of patterns related to the four main constructs of meaningful learning showed that involving practicum students in an experiential learning cycle through written accounts of CIs and enabling them to vicariously experience CIs made meaningful contributions to their learning outcomes. Despite their context-dependency, selection of CIs containing events that are of concern to many foreign language teaching settings created real-life like experiences for student teachers. Given pandemic closures, practicum students are not able to put the academic course content they learnt in teacher education programs into practice in practicum schools and it is not possible for them to encounter such 
challenging real conditions and make decisions informed by theory. As a result, we argue that developing awareness in student teachers regarding critical incidents and helping them build up a repertoire of coping strategies that they can draw on when faced with critical events once they start teaching is of great value to bridge the theory-practice divide. Handling pedagogical dilemmas at pre-service level also assists teacher candidates in understanding the significance and functionality of content and pedagogical knowledge and as well transferable skills in dealing with complicated real-world problems. Moreover, as such authentic learning experiences teach student teachers to turn these unwelcome situations into learning opportunities, novice teachers will feel more confident and will not get discouraged when faced with critical cases particularly in the first years of teaching often indicated as a period of reality shock (Farrell \& Baecher, 2017).

Nevertheless, despite encouraging findings, this research was a small scale case study conducted at one teacher education program, thus it might not be necessarily representative. Second, this study was limited to investigating practicum students' perceptions of their vicarious experiences, which proves the need for longitudinal studies that systematically track this cohort of student teachers into bricks-andmortar classrooms to investigate the effects of this intervention on novice teachers' actual conceptualization of and reactions to CIs.

Data availability The datasets generated/used during the current study are available from the author on reasonable request.

\section{Declarations}

Consent to participate A written informed consent briefing about the significance and purpose of the study, asking for giving consent for voluntary participation and informing about the ensurance of anonymity and confidentiality was signed by all participants.

Conflict of interest The author declares no conflicts of interest.

\section{References}

Anderson, T., Rourke, L., Garrison, D. R., \& Archer, W. (2001). Assessing teaching presence in a computer conferencing context. Journal of Asynchronous Learning Networks, 5(2), 1-17. https://auspa ce.athabascau.ca/bitstream/handle/2149/725/assess? sequence=1. Accessed 18 Nov 2020.

Ausubel, D. P. (1963). The psychology of meaningful verbal learning: An introduction to school learning. Grune \& Stratton.

Ausubel, D. P. (2000). The acquisition and retention of knowledge: A cognitive view. Kluwer Academic Publishers.

Babaii, E., Molana, K., \& Nazari, M. (2020). Contributions of assessment-related critical incidents to language teacher identity development. Innovation in Language Learning and Teaching. https://doi. org/10.1080/17501229.2020.1824234.

Bashan, B., \& Holsblat, R. (2017). Reflective journals as a research tool: The case of student teachers' development of teamwork. Cogent Education, 4(1), 1-15. https://doi.org/10.1080/2331186X.2017. 1374234 . 
Bohon, L. L., McKelvey, S., Rhodes, J. A., \& Robnolt, V. J. (2017). Training for content teachers of English language learners: Using experiential learning to improve instruction. Teacher Development, 21(5), 609-634. https://doi.org/10.1080/13664530.2016.1277256.

Bonwell, C., \& Eison, J. (1991). Active learning: Creating excitement in the classroom. (No. ISBN-1878380-06-7; ISSN-0884-0040). https://files.eric.ed.gov/fulltext/ED336049.pdf. Accessed 11 Dec 2020.

Brandenburg, R., \& McDonough, S. (2017). Using critical incidents to reflect on teacher educator practice. In R. Brandenburg, K. Glasswell, M. Jones, \& J. Ryan (Eds.), Reflective theory and practice in teacher education (pp. 223-237). Springer. https://doi.org/10.1007/978-981-10-3431-2_12.

Brubaker, N. D. (2015). Critical moments in negotiating authority: Grading, accountability and teacher education. Teaching Education, 26(2), 222-246. https://doi.org/10.1080/10476210.2014.996742.

Burns, A., \& Rochsantiningsih, D. (2006). Conducting action research in Indonesia: Illustrations and implications. Indonesian Journal of English Language Teaching, 2(1), 21-35. https://doi.org/10. 25170/ijelt.v2i1.

Cheung, R., \& Vogel, D. (2013). Predicting user acceptance of collaborative technologies: An extension of the technology acceptance model for e-learning. Computers and Educations, 63, 160-175. https://doi.org/10.1016/j.compedu.2012.12.003.

Chien, C. W. (2017). Analysis of six Taiwanese EFL student teachers' professional learning from writing, discussing, and analyzing critical incidents. Teacher Development, 22(3), 339-354. https://doi.org/ 10.1080/13664530.2017.1403368.

Cohen, L., Manion, L., \& Morrison, K. (2007). Research methods in education. Routledge Falmer.

Creswell, J. W. (2007). Qualitative inquiry and research method: Choosing among five approaches. Sage.

Curtis, D. D., \& Lawson, M. J. (2001). Exploring collaborative online learning. Journal of Asynchronous Learning Networks, 5(1), 21-34. https://doi.org/10.24059/olj.v5i1.1885.

Ebadi, S., \& Rahimi, M. (2019). Mediating EFL learners' academic writing skills in online dynamic assessment using Google docs. Computer Assisted Language Learning, 32(5-6), 527-555. https:// doi.org/10.1080/09588221.2018.1527362.

Elo, S., \& Kyngäs, H. (2008). The qualitative content analysis process. Journal of Advanced Nursing, 62(1), 107-115. https://doi.org/10.1111/j.1365-2648.2007.04569.x.

Farrell, T. S. (2008). Critical incidents in ELT initial teacher training. ELT Journal, 62(1), 3-10. https:// doi.org/10.1093/elt/ccm072.

Farrell, T. S. C., \& Baecher, L. (2017). Reflecting on critical incidents in language education. Bloomsbury.

Flores, M. A. (2016). Teacher education curriculum. In J. Loughran \& M. L. Hamilton (Eds.), International handbook of teacher education (pp. 187-230). Springer. https://doi.org/10.1007/ 978-981-10-0366-0_5.

Flores, M. A., \& Gago, M. (2020). Teacher education in times of Covid-19 pandemic in Portugal: National, institutional and pedagogical responses. Journal of Education for Teaching. https://doi. org/10.1080/02607476.2020.1799709.

Garrison, D. R., Cleveland-Innes, M., Koole, M., \& Kappelman, J. (2006). Revisiting methodological issues in the analysis of transcripts: Negotiated coding and reliability. The Internet and Higher Education, 9(1), 1-8. https://doi.org/10.1016/j.iheduc.2005.11.001.

Griffin, M. L. (2003). Using critical incidents to promote and assess reflective thinking in preservice teachers. Reflective Practice, 4(2), 207-220. https://doi.org/10.1080/14623940308274.

Hakkarainen, P. (2009). Designing and implementing a PBL course on educational digital videoproduction: Lesson learned from a design-based research. Educational Technology Research \& Development, 57(2), 211-228. https://doi.org/10.1007/s11423-007-9039-4.

Hakkarainen, P., Saarelainen, T., \& Ruokamo, H. (2007). Towards meaningful learning through digital video supported, case based teaching. Australasian Journal of Educational Technology, 23(1), 87-109. https://doi.org/10.14742/ajet.1275.

Hall, J. M., \& Townsend, S. D. C. (2017). Using critical incidents and E-portfolios to understand the emergent practice of Japanese student-teachers of English. Teaching and Teacher Education, 62, 1-9. https://doi.org/10.1016/j.tate.2016.10.017.

Harrison, J. K., \& Lee, R. (2011). Exploring the use of critical incident analysis and the professional learning conversation in an initial teacher education programme. Journal of Education for Teaching, 37(2), 199-217. https://doi.org/10.1080/02607476.2011.558285.

Howland, J. L., Jonassen, D. H., \& Marra, R. M. (2014). Meaningful learning with technology. Pearson Education Limited. 
Hsu, Y. C., \& Shiue, Y. M. (2018). Exploring the influence of using collaborative tools on the community of inquiry in an interdisciplinary project-based learning context. EURASIA Journal of Mathematics, Science and Technology Education, 14(3), 933-945. https://doi.org/10.12973/ejmste/81149.

Huang, Y. M., Chiu, P. S., Liu, T. C., \& Chen, T. S. (2011). The design and implementation of a meaningful learning-based evaluation method for ubiquitous learning. Computers \& Education, 57(4), 2291-2302. https://doi.org/10.1016/j.compedu.2011.05.023.

Ishtaiwa, F. F., \& Aburezeq, I. M. (2015). The impact of Google docs on student collaboration: A UAE case study. Learning, Culture and Social Interaction, 7, 85-96. https://doi.org/10.1016/j.lcsi.2015. 07.004.

Jonassen, D. H. (1995). Supporting communities of learners with technology: A vision for integrating technology with learning in schools. Educational Technology, 35(4), 60-63. https://www.jstor.org/ stable/44428289. Accessed 1 Nov 2020.

Jonassen, D., \& Strobel, J. (2006). Modeling for meaningful learning. In D. Hung \& M. S. Khine (Eds.), Engaged learning with emerging technologies (pp. 1-27). Springer. https://doi.org/10. 1007/1-4020-3669-8_1.

Karami, M., Karami, Z., \& Attaran, M. (2013). Integrating problem-based learning with ICT for developing trainee teachers' content knowledge and teaching skill. International Journal of Education and Development Using Information and Communication Technology, 9(1), 36-49. https://www.learn techlib.org/p/111904/. Accessed 9 Nov 2020.

Kemmis, S., \& McTaggart, R. (1988). The action research planner. Melbourne:Deakin University Press.

Kolb, D. A. (1984). Experiential learning: Experience as the source of learning and development. Prentice-Hall. https://doi.org/10.1002/job.4030080408.

Kolb, A. Y., \& Kolb, D. A. (2017). Experiential learning theory as a guide for experiential educators in higher education. Experiential Learning Theory in Higher Education, 1(1), 7-44. https://nsuworks. nova.edu/elthe/vol1/iss1/7. Accessed 1 Sep 2020.

Lee, C. B. (2018). Initial development of the meaningful learning with technology scale (MeLTS) for high-school students. Interactive Learning Environments, 26(2), 163-174. https://doi.org/10.1080/ 10494820.2017 .1283336$.

Lin, Y. T., Chang, C. H., Hou, H. T., \& Wu, K. C. (2016). Exploring the effects of employing Google docs in collaborative concept mapping on achievement, concept representation, and attitudes. Interactive Learning Environments, 24(7), 1552-1573. https://doi.org/10.1080/10494820.2015.1041398.

Lipponen, L., \& Lallimo, J. (2004). Assessing applications for collaboration: From collaboratively usable applications to collaborative technology. British Journal of Educational Technology, 35(4), 433442. https://doi.org/10.1111/j.0007-1013.2004.00402.x.

Mayer, R. (2004). Should there be a three-strikes rule against pure discovery learning? The case for guided methods of instruction. American Psychologist, 59(1), 14-19. https://doi.org/10.1037/0003066X.59.1.14.

McGarr, O., \& McCormack, O. (2016). Counterfactual mutation of critical classroom incidents: Implications for reflective practice in initial teacher education. European Journal of Teacher Education, 39(1), 36-52. https://doi.org/10.1080/02619768.2015.1066329.

McLellan, H. (2004). The case for case-based teaching in online classes. Educational Technology, 44(4), 14-18. https://www.jstor.org/stable/44428918. Accessed 1 Sept 2020.

Meijer, P. C., de Graaf, G., \& Meirink, J. (2011). Key experiences in student teachers' development. Teachers and Teaching: Theory and Practice, 17(1), 115-129. https://doi.org/10.1080/13540602. 2011.538502 .

Miles, M. B., \& Huberman, A. M. (1994). Qualitative data analysis: An expanded sourcebook. Sage.

Moyo, N. (2020). Covid-19 and the future of practicum in teacher education in Zimbabwe: Rethinking the 'new normal' in quality assurance for teacher certification. Journal of Education for Teaching. Advance online publication. https://doi.org/10.1080/02607476.2020.1802702.

Nasri, M. N., Husnin, H., Mahmud, S. N. D., \& Halim, L. (2020). Mitigating the COVID-19 pandemic: A snapshot from Malaysia into the coping strategies for pre-service teachers' education. Journal of Education for Teaching. https://doi.org/10.1080/02607476.2020.1802582.

Sadaf, A., \& Olesova, L. (2017). Enhancing cognitive presence in online case discussions with questions based on the practical inquiry model. The American Journal of Distance Education, 31(1), 56-59. https://doi.org/10.1080/08923647.2017.1267525.

Shapira-Lishchinsky, O. (2011). Teachers' critical incidents: Ethical dilemmas in teaching practice. Teaching and Teacher Education, 27(3), 648-656. https://doi.org/10.1016/j.tate.2010.11.003. 
Sturman, A. (1997). Case study methods. In J. P. Keeves (Ed.), Educational research, methodology and measurement: An international handbook (pp. 61-66). Elsevier Science.

Svinicki, M. D., \& Dixon, N. M. (1987). The Kolb model modified for classroom activities. College Teaching, 35(4), 141-146. https://doi.org/10.1080/87567555.1987.9925469.

Tripp, D. (1993). Critical incidents in teaching. Routledge.

Veenman, S. (1984). Perceived problems of beginning teachers. Review of Educational Research, 54(2), 143-178. https://doi.org/10.3102/00346543054002143.

Vygotsky, L. S. (1978). Mind and society. Harvard University Press.

YÖK. (2019). Higher Education System in Turkey. https://www.yok.gov.tr/Documents/Yayinlar/Yayin larimiz/2019/Higher_Education_in_Turkey_2019_en.pdf. Accessed 14 Apr 2021.

Publisher's note Springer Nature remains neutral with regard to jurisdictional claims in published maps and institutional affiliations. 